\title{
Impaired intestinal barrier function measured by differently sized polyethylene glycols in patients with chronic renal failure
}

\author{
M Magnusson, K-E Magnusson, T Sundqvist, T Denneberg
}

\begin{abstract}
The intestinal mucosa plays a fundamental role as the site for absorption of nutrients, and as an important barrier from potentially harmful agents in the intestinal lumen. Little is known of the permeability properties of the intestinal mucosa in uraemic patients. The intestinal permeability to differently sized polyethylene glycols (PEGs; range 326-1254 daltons) was studied in nine patients with chronic renal failure (24 hour endogenous creatinine clearance $5-27 \mathrm{ml} /$ minute). The maximum 24 hour urinary recovery of PEGs was decreased in the uraemic patients but relatively more of the larger than the smaller PEGs were found in these patients. The results suggest a reduced urinary recovery of PEGs caused by renal dysfunction but also a relatively increased intestinal permeability to larger PEGs in the uraemic patients.
\end{abstract}

Although the intestinal membranes are the site of absorption of nutrients, they also provide a barrier that prevents potentially harmful agents from leaving the intestinal lumen. ${ }^{1}$ However, infections such as rotavirus, and villous atrophy caused in disorders such as coeliac disease, can lead to altered barrier properties. ${ }^{2-4}$ Arthritis in association with chronic inflammatory bowel diseases has been thought to depend on absorption of immunogenic substances via the altered gut mucosa. ${ }^{5}$ Furthermore, several potentially toxic substances are produced by the bacterial flora in the intestinal lumen and these may accumulate after absorption in the uraemic state. ${ }^{6-9}$

Histological changes, including reduction of villous height, increased crypt depth, and infiltration of inflammatory cells and functional changes such as decreased activity of dipeptidases and increased activities of disaccharidases, have been shown in the intestine in patients with chronic uraemia. ${ }^{10-13}$

Although proteinaceous macromolecules are thought to be digested in the lumen and further broken down during the absorption process, some material may enter the bloodstream. ${ }^{14}$ Several studies have indicated that even larger molecules and particles can be transmitted across the intestinal membranes by persorption. ${ }^{15}$

Several inert or weakly metabolised molecules have been used to assess intestinal permeability, including ${ }^{51} \mathrm{Cr}$-EDTA, urea, mannitol, rhamnose/lactulose, and polyethylene glycols..$^{16-18}$

We have recently investigated the intestinal permeability to differently sized polyethylene glycols (PEGs) (range 326-1162 daltons) and their recovery in urine after intravenous injection in rats with chronic uraemia. ${ }^{19-20}$ Firstly, we found that the intestinal permeability to the larger PEG molecules (range 546-1162 daltons) increased in the uraemic rats. Secondly, intestinal permeability decreased in normal and uraemic rats fed a low protein diet. The investigation also showed that intravenously administrated PEGs were excreted without glomerular exclusion in the size range used (326-1162 daltons) in both normal rats and those with chronic uraemia.

This study aimed to investigate the intestinal permeability to differently sized polyethylene glycols (range 326-1162 daltons) in nine patients with chronic renal failure.

We found an over all reduction in intestinal permeability of PEGs but a relatively increased permeability to larger PEG molecules (414-898 daltons) in patients with chronic uraemia. The permeability profiles of the uraemic patients and normal subjects were also compared with the results of computer simulations of a multicompartment model, focussing on the effects of reduced renal excretion capacity.

\section{Patients and methods}

PATIENTS

The uraemic group consisted of nine patients with stable chronic renal insufficiency without overt uraemic symptoms. None had undergone gastrointestinal surgery or had any history of gastrointestinal disease. The patients were in hospital during the study and most were on an unrestricted protein intake diet. One patient had a terminal uraemia and was on a moderately protein restricted diet of approximately $40 \mathrm{~g}$ per day (patient 9 in Table I). Daily energy intake varied between 1800-2200 kcal. Phosphate binders, vitamin B, and calcium carbonate were given and antihypertensives were added when needed. No patient was treated with glucocorticoides or non-steroidal anti-inflammatory drugs (NSAIDs). Further patient data are given in Table I. The control group comprised six healthy volunteers (four women and two men) with no history of renal or gastrointestinal disease (Table I). The study was approved by the local ethical committee.

\section{PEG TEST}

A mixture of PEG 400 and PEG 1000 (range 326-1244 daltons) (100 mg PEG 400 and $2.5 \mathrm{~g}$ PEG 1000 dissolved in $10 \mathrm{ml}$ of water, obtained as Macrogolum from Apoteksbolaget, Stock- 
TABLE I Details of uraemic patients and control subjects

\begin{tabular}{|c|c|c|c|c|c|c|}
\hline Patient & Sex & $\begin{array}{l}\text { Age } \\
\text { (yrs) }\end{array}$ & Diagnosis & $\begin{array}{l}\text { Serum } \\
\text { creatinine } \\
\text { ( } \mu \text { molll) }\end{array}$ & $\begin{array}{l}\text { Serum urea } \\
\text { (mmolll) }\end{array}$ & $\begin{array}{l}24 \mathrm{hr} \text { creatinine } \\
\text { clearance }(\text { ml/ } \\
\left.\text { min } / 1 \cdot 73 \mathrm{~m}^{2}\right)\end{array}$ \\
\hline $\begin{array}{l}1 \\
2 \\
3 \\
4 \\
5 \\
6 \\
7 \\
8 \\
9 \\
\text { Mean } \\
\text { Range }\end{array}$ & $\begin{array}{l}\mathrm{M} \\
\mathbf{M} \\
\mathbf{M} \\
\mathbf{F} \\
\mathbf{M} \\
\mathbf{M} \\
\mathbf{F} \\
\mathbf{M} \\
\mathbf{F}\end{array}$ & $\begin{array}{l}35 \\
73 \\
55 \\
75 \\
54 \\
82 \\
51 \\
63 \\
66 \\
62 \\
35-82\end{array}$ & $\begin{array}{l}\text { CGN } \\
\text { HN } \\
\text { CGN } \\
\text { NSC } \\
\text { CGN } \\
\text { NSC } \\
\text { PC } \\
\text { CGN } \\
\text { CPN }\end{array}$ & $\begin{array}{l}274 \\
355 \\
451 \\
413 \\
796 \\
446 \\
542 \\
667 \\
586 \\
503 \\
274-796\end{array}$ & $\begin{array}{l}20 \\
23 \\
27 \\
41 \\
31 \\
33 \\
22 \\
30 \\
45 \\
30 \\
20-45\end{array}$ & $\begin{array}{l}27 \\
18 \\
16 \\
12 \\
11 \\
10 \\
9 \\
8 \\
5 \\
13 \\
5-27\end{array}$ \\
\hline $\begin{array}{l}\text { Controls: } \\
\text { Mean } \\
\text { Range }\end{array}$ & & $\begin{array}{l}31 \\
23-41\end{array}$ & & $\begin{array}{l}83 \\
63-99\end{array}$ & $\begin{array}{l}5 \\
3-7\end{array}$ & $\begin{array}{l}99 \\
69-124\end{array}$ \\
\hline
\end{tabular}

$\mathrm{CGN}=$ chronic glomerulonephritis; $\mathrm{HN}=$ hydronephrosis; $\mathrm{NSC}=$ nephrosclerosis; $\mathrm{PC}=$ polycystic disease; $\mathrm{CPN}=$ chronic pyelonephritis.

holm, Sweden) was given orally in $150 \mathrm{ml}$ of water after overnight fasting. Ingestion of food and drugs was not allowed during the first two hours. Urine was collected over six, 24 , and 48 hours. The urine was frozen at $-20^{\circ}$ for further analysis of PEGs. When the urinary recovery is discussed below it refers to the 24 hour recovery unless otherwise stated.

\section{ANALYSES OF PEGS}

Six, 24, and 48 hour samples of urine were analysed. Since the urine contained visible flocculated material which seemed to interfere with the separation and analysis of PEGs according to a previously published procedure ${ }^{21}$ the extraction of PEG from the urine was modified. Thus, $6 \mathrm{ml}$ samples and controls with known amounts of PEGs in duplicates were mixed with $1.5 \mathrm{ml}$ trichloroacetic acid (TCA 50\%) for 10 minutes at room temperature and centrifuged for 10 minutes at $3700 \mathrm{rpm}(\approx 1150 \mathrm{~g})$ in a Wifug Doctor Centrifuge (Wifug, Stockholm, Sweden). Then $7 \mathrm{ml}$ of the combined supernatants of the duplicates were neutralised to around $\mathrm{pH} 7$ with $0.5 \mathrm{~mol} / 1 \mathrm{NaOH}$, as measured with $\mathrm{pH}$ indicator paper. Some $6 \mathrm{ml}$ was then mixed in a vortex mixer with $3.7 \mathrm{~g}$ Amberlite MB-3 mixed anionic and cationic resin (BDH Ltd, England), inverted repeatedly for 30 minutes at $37^{\circ} \mathrm{C}$, mixed with new resin, and inverted for another 30 minutes at $37^{\circ} \mathrm{C}$. A $2 \mathrm{ml}$ sample was freeze dried overnight, dissolved in methanol $(42 \%)$ and water $(58 \%)$, filtered through a $0.45 \mu \mathrm{m}$ filter, and analysed with high performance liquid chromatography (HPLC; HSRI 931, Tecator, Sweden, equipped with reverse phase C-8 column, Lichrosorb RP-8 Fertigkolonnen, Merck AG, Darmstadt, West Germany). The pressure was about $20 \mathrm{MPa}$ and the flow rate (waste mode) around $40 \mathrm{ml} /$ hour. By comparing the peak height of each PEG molecular weight species in the urine with the amount given orally, the percentage recovery of each PEG molecular size was calculated.

CHARACTERISTICS OF THE MUCOSAL BARRIER Based on the recovery of different sized PEGs in each patient, the barrier was characterised in the following ways. Firstly by the breakpoint (dalton) - that is the PEG size where the recovery

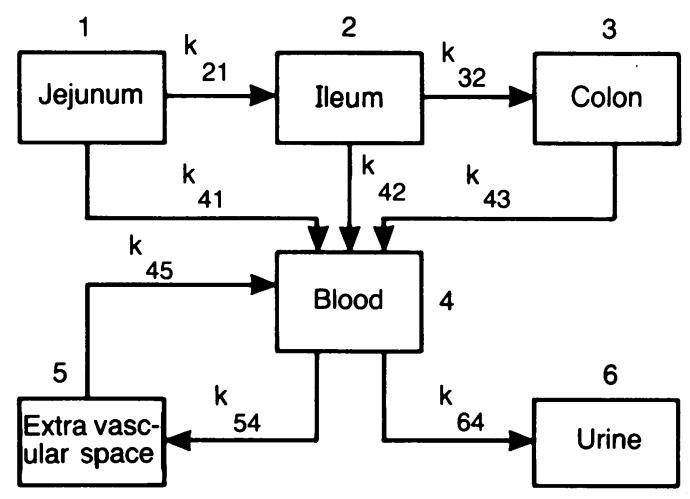

Figure 1: Graphic representation of the multicompartment model, where kij represent the rate constant from compartment $i$ to $j$.

(R) $(\%)=(\mathrm{R} \max -\mathrm{R} \min ) / 2+\mathrm{R} \min . \mathrm{R} \max$ and $\mathrm{R}$ min are the maximum and minimum urinary recoveries of the molecules used; this parameter describes the PEG size where $50 \%$ of the intestinal filtering is expressed. ${ }^{22}$ Secondly by the slope of the recovery values for increasing PEG size, since the intestinal exclusion of molecules because of size was roughly linear and inversely proportional to the molecular weight. To describe the correlation between urinary recovery and molecular weight, a linear correlation coefficient was calculated by using the eight PEG sizes symmetrically surrounding the breakpoint. This was done because the urinary recovery patterns, as a result of the relative low recovery, did not fit well with a previously described model. ${ }^{23}$

\section{COMPUTER SIMULATIONS OF URINARY RECOVERY} IN RENAL FAILURE

The passage of molecules from the intestine to the urine was approximated with a multicompartment model (Fig 1), and simulated for different critical parameters, using Stella software (High Performance System Inc, Lyme, New Hampshire, USA) and a Macintosh SE computer. The transit times between the intestinal segments were described by ramp functions. During the first 30 minutes, absorption was assumed to occur from a segment corresponding to the jejunum, and from 30 to 60 minutes the intestinal contents were transported further into the ileum. Absorption from the ileum took place only between 60 and 105 minutes, when the transport to the colon started. Absorption from the colon alone occurred between 135 and 360 minutes, when the simulation ended. The rate

TABLE II Mucosal barrier characteristics calculated from the urinary recovery of polyethelyne glycols (PEGs) in the uraemic and control groups. Values are mean (SEM)

\begin{tabular}{llll}
\hline $\begin{array}{l}\text { Barrier } \\
\text { characteristics }\end{array}$ & Controls $(n=6)$ & Uraemic $(n=9)$ & $\begin{array}{l}\text { Significance } \\
(p<)\end{array}$ \\
\hline $\begin{array}{l}\text { Breakpoint } \\
\text { (Da PEG) }\end{array}$ & $541(60)$ & $688(25)$ & 0.05 \\
$\begin{array}{c}\text { Regression } \\
\text { coefficient† }\end{array}$ & $3.92(0.98)$ & $1.18(0.42)$ & 0.01 \\
\hline
\end{tabular}

^Breakpoint Da PEG, is the PEG molecular weight at which $50 \%$ * Breakpoint Da PEG, is the PEG molecul
of the intestinal filtering has occurred.

of the intestinal filtering has occurred.
The regression coefficient is based on a linear approximation of tThe regression coefficient is based on a linear approximation of
the recovery of molecules according to molecular weight for the the recovery of molecules according to molecular weight for
eight molecules surrounding the breakpoint of each individual. 


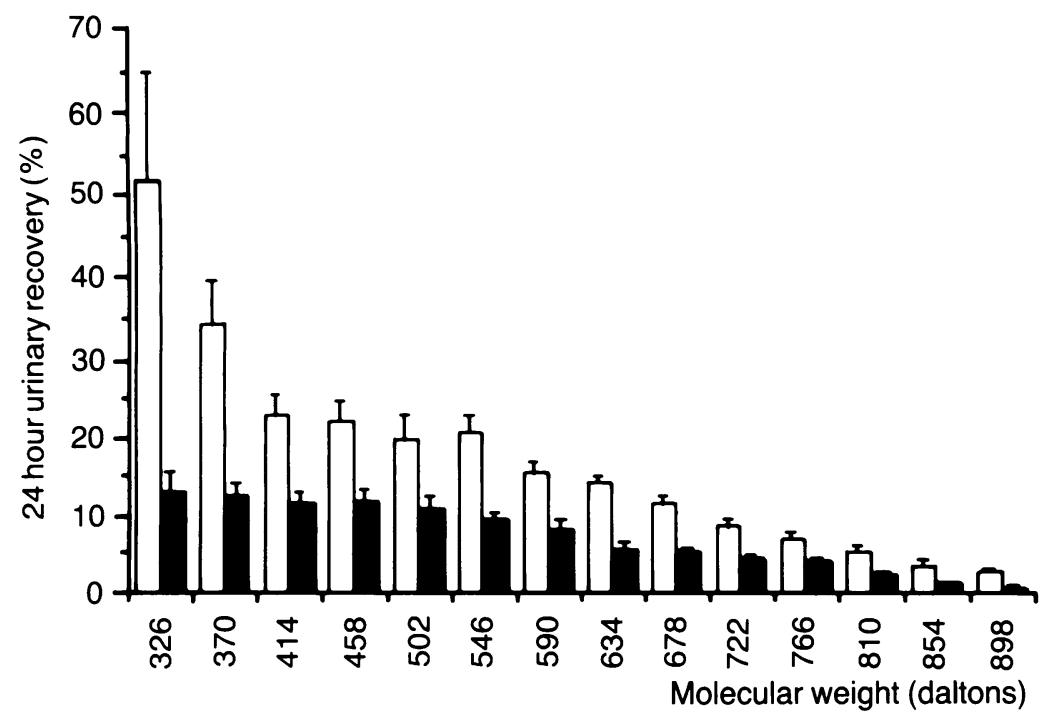

Figure 2: Twenty four hour urinary recovery of polyethylene glycols (PEGs) in the control group (open bars) and in the uraemic group (closed bars). The recovery is significantly higher for all molecular weight species in the control group $(p<0 \cdot 05-0.001)$.
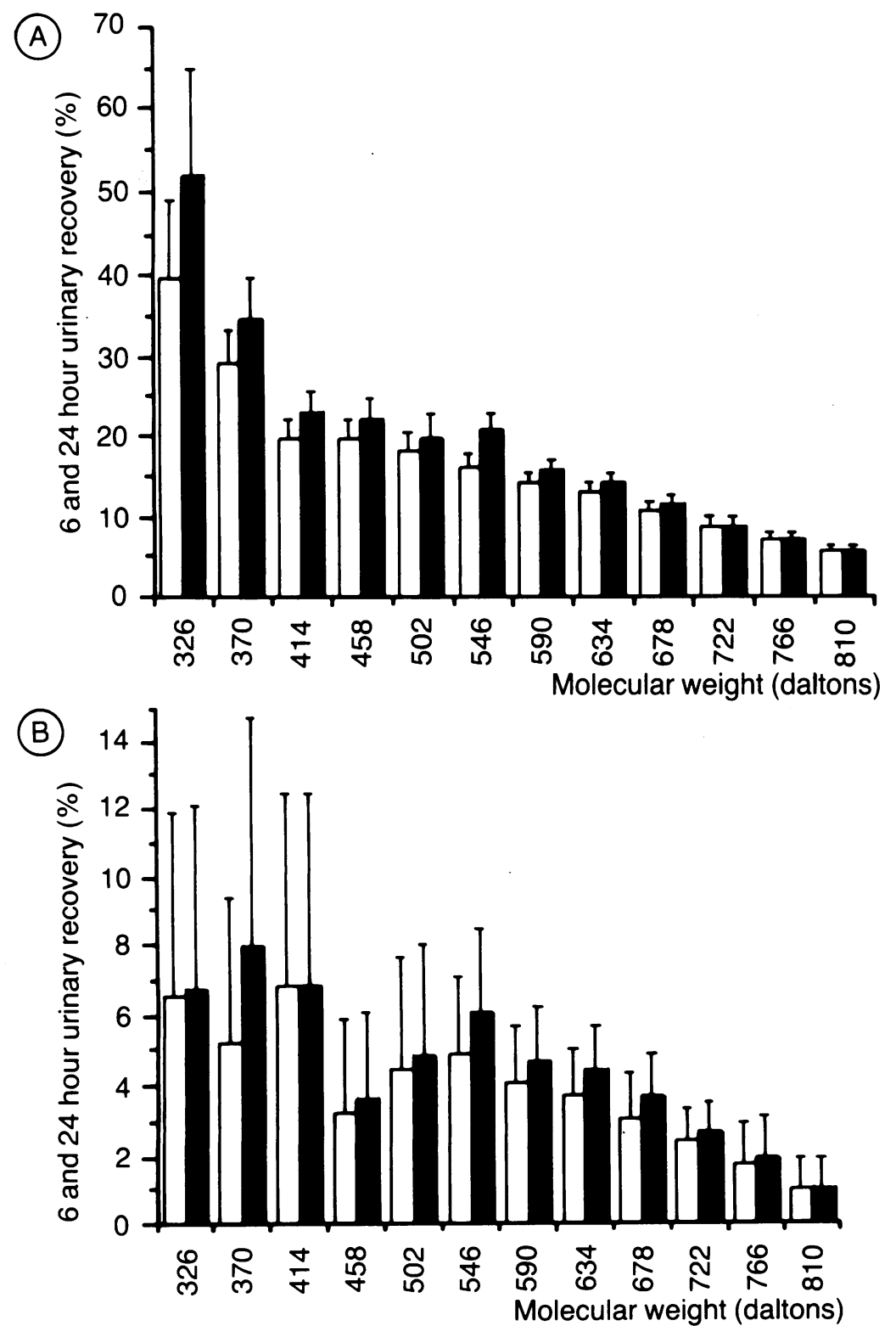

Figure 3: (A) Six hour (open bars) and 24 hour (closed bars) urinary recovery of polyethylene glycols (PEGs) in the control group. Only small quantities of small molecules (range 326-546 daltons) are excreted between 6 and 24 hours. (B) Six hour (open bars) and 24 hour (closed bars) urinary recovery of PEGs in three uraemic patients (nos 7-9 in Table I). Small quantities are excreted between 6 and 24 hours. constants $\left(k_{41}, k_{42}, k_{43}\right)$ for the absorption of different sized PEG molecules from the jejunum, ileum, and colon, respectively, were calculated from exponential functions applied to steady state intestinal perfusion data in man. ${ }^{2}$ The rate constants describing exchange with the extravascular space and renal clearance were taken from earlier results obtained in pigs. ${ }^{24}$ With regard to the aims of the present investigation, the simulations were performed by changing the rate constant describing the passage from blood to urine between $20 \%$ to $150 \%$ of the basal value - the value of the rate constant $k_{64}$ for each molecular weight species of PEG was changed between $0 \cdot 2^{\star} \mathrm{k}_{64}$ and $1 \cdot 5^{\star} \mathrm{k}_{64}$.

\section{LABORATORY TESTS AND STATISTICS}

Serum and urine creatinine and serum urea concentrations were determined by routine methods at the Department of Clinical Chemistry, University Hospital, Linköping, Sweden. The results are given as mean (SEM) and the statistical calculations were performed by Student's $t$ test for unpaired data.

\section{Results}

The 24 hour urinary recovery of PEGs in the uraemic and control groups are shown in Figure 2. The reduced recovery of PEGs in the uraemic group is statistically significant for all molecular weight species $(\mathrm{p}<0.05-0.001)$. The six and 24 hour urinary recovery in the control group and in three uraemic patients (patients 7-9) are shown in Figures $3 \mathrm{~A}$ and $\mathrm{B}$. As the Figures indicate, only minor quantities of the smaller molecules (326-414 daltons PEG) are excreted between six and 24 hours, particularly in the control group (Fig 3A). This pattern was not so striking in the three uraemic patients (Fig 3B). Negligible amounts of PEGs were, however, detected in 24 48 hour urine samples in both the control and in the uraemic groups.

Table II shows the calculated permeability characteristics of the two groups. The breakpoint was significantly shifted towards a larger value that is to the right in Figure 1 - in the uraemic group $(p<0.05)$. Moreover, the regression coefficient was lower in the uraemic group $(\mathrm{p}<0.01)$.

The relative urinary recovery of the molecules, compared with the recovery of 326 daltons is shown in Figure 4, suggesting a relative increased recovery of larger PEGs in the uraemic patients. The simulated urinary recovery of PEG 400 (range 282-590 daltons) with various renal function is displayed in Figure 5A. The results suggest that the over all urinary recovery of molecules is decreased when the renal excretion capacity is reduced. Furthermore, the simulation also suggests that there would be a relatively increased recovery of the larger molecules when the renal clearance is reduced (Fig 5B). The difference was much less pronounced, however, than in Figure 4. The breakpoint did not change significantly solely by reducing the renal function. It varied only between $397-408$ daltons in Figure 5A, when the renal excretion was altered from 150 to $20 \%$. 


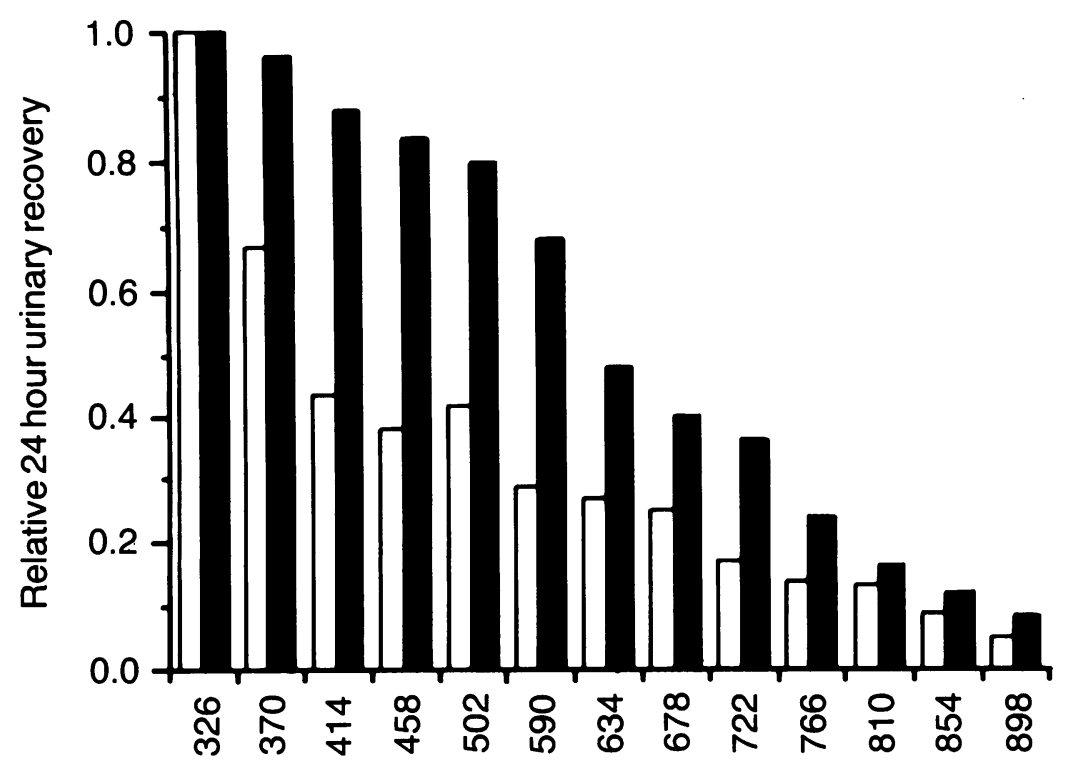

Molecular weight (daltons)

Figure 4: Relative 24 hour urinary recovery of polyethylene glycols (PEGs) in the control group (open bars) and in the uraemic group (closed bars). The recovery of 326 dalton PEG in each group has been set to $1 \cdot 0$.
540 (60) daltons in the healthy subjects (Table II). This indicates that relatively more larger molecules were recovered in the uraemic patients than in the control subjects. The relative urinary recovery of the molecules, compared with that of 326 dalton PEG, is shown in Figure 4. For comparison the recovery of 326 dalton has been set to 1.0 in both groups.

The urinary recovery of orally given PEGs was inversely proportional to molecular weight (Fig 2). The intestinal exclusion due to the size of the probes probably does not show a truly linear dependence, but it seems reasonable to use a linear approximation to describe the data for the limited size range of probes used. A gut mucosa with an increased selectivity will give a comparatively low recovery of large molecules and hence a steeper slope of the curve, resulting in a larger negative regression coefficient. On the contrary, a less selective gut, that allows larger molecules to pass more freely, would give a flatter curve and then a comparatively smaller value of the regression coefficient. Using this approach, we interpret the smaller regression coefficient in the uraemic group as a sign of a reduced intestinal selectivity towards the larger PEGs (Table II).

An explanation for the increased breakpoint and the smaller regression coefficient in the uraemic patients could be a higher relative excretion of the larger PEGs in the uraemic patients compared with subjects with normal renal function.

The opposite was found, however, when PEGs were given intravenously to uraemic rats. The overall 24 hour recovery was decreased for all molecular weight species as could be expected because of the impaired renal function. ${ }^{20}$ But the urinary recovery of the smaller molecules (326590 daltons) was relatively higher than the recovery of the larger ones (634-1162 daltons). The opposite was found in the control rats, in which the urinary recovery of the smaller molecules was lower than the recovery of the larger PEGs. ${ }^{20}$ Furthermore, the urinary recovery of the larger PEGs (590-1162 daltons) increased in direct proportion to the molecular weight in both
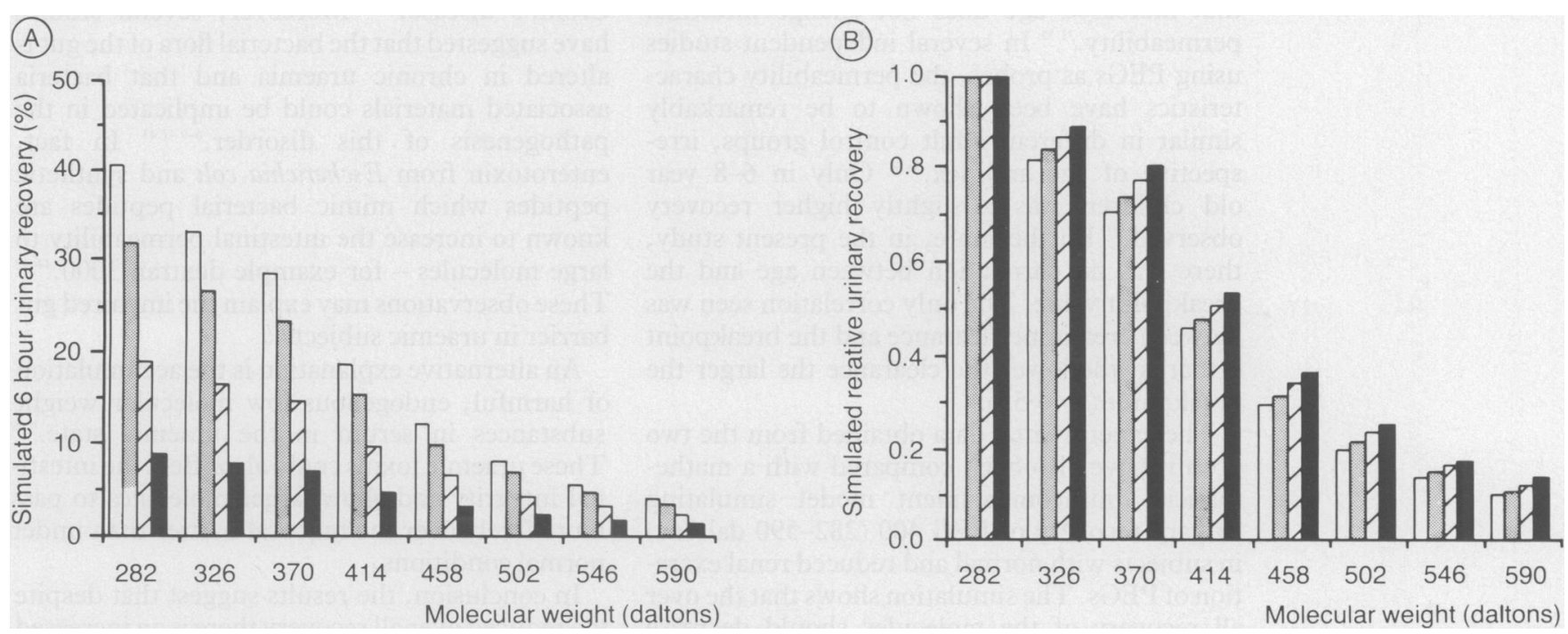

Figure 5: (A) Computer simulated 6 hour urinary recovery of different sized polyethylene glycols (PEGs) in subjects with $150 \%$ of normal renal excretion ( $\square$ ). $100 \%$ of normal renal excretion $(\square)$, reduced renal excretion of $50 \%(\mathbb{Z})$ and reduced renal excretion of $20 \%(\square)$. (B) Simulated relative 6 hour urinary recovery in the four groups with different renal excretion. $150 \%$ ( $\square$ ) of normal renal excretion, $100 \%(\square), 50 \%$ (D) and $20 \%(\square)$. The recovery of 282 dalton $P E G$ has been set to $1 \cdot 0$ in each case. 
normal and uraemic rats, which was probably the result of a larger distribution volume of the smaller tracers. ${ }^{20}$ This suggests that a simple comparison of ratios between larger and smaller molecules might not completely compensate for the reduced renal function in uraemic subjects. ${ }^{20}$ Moreover, intravenous administration of PEGs suggested that there was no glomerular exclusion of PEGs up to 1162 daltons. ${ }^{20}$ Neither have previous studies shown any reduced renal excretion of PEG 400,600 , or $1000 .^{26-29}$

Although there was no sign of altered intestinal transit time in the uraemic subjects, these changes could affect the urinary recovery of PEGs. ${ }^{16}$ However, a recent study has shown that moderate changes in gastric emptying time and intestinal transit time have a negligible effect on the relative recoveries of di- and monosaccharides. ${ }^{25}$ In another study the authors were unable to show a correlation between the absorption of polyethylene glycols and the gut transit time. ${ }^{30}$ These results should also have a bearing on the relative recovery and the breakpoint of differently sized PEGs.

Differences in the distribution volume of the molecules in the two groups could cause disparity in the urinary recovery between uraemic and control subjects. Previous studies have indeed shown an increased distribution volume of the smaller PEGs compared with the larger molecules. ${ }^{24}{ }^{29}$ However, this is an unlikely explanation of the difference, since there was a negligible increase in recovery between six and 24 hours in the control group. Moreover, the breakpoint - that is the molecular size where $50 \%$ of the intestinal filtering is expressed - was very similar for the six hour and 24 hour urinary recovery (531 (53) and 539 (49) daltons PEG, respectively). Delayed urinary excretion of the smaller molecules in the control subjects, as indicated in Fig 3A, compared with the uraemic patients (Fig 3B) would be more likely to increase the breakpoint in the control subjects.

The mean age was higher in the uraemic than in the control subjects (Table I), which may have influenced the permeability tests. Earlier studies using sugars as markers have shown, however, that increased age does not change intestinal permeability. ${ }^{312}$ In several independent studies using PEGs as probes, the permeability characteristics have been shown to be remarkably similar in different adult control groups, irrespective of age and sex. ${ }^{334}$ Only in 6-8 year old children was a slightly higher recovery observed. ${ }^{21}$ Furthermore, in the present study, there was no correlation between age and the breakpoint value. The only correlation seen was between creatinine clearance and the breakpoint - that is, the lower the clearance the larger the breakpoint $(r=0.55)$.

The experimental data obtained from the two groups have also been compared with a mathematical multicompartment model simulating urinary recovery of PEG 400 (282-590 daltons) in subjects with normal and reduced renal excretion of PEGs. The simulation shows that the over all recovery of the molecules should decrease when the renal function is reduced (Fig 5A). Furthermore, the relative recovery of the larger molecules should increase compared with the smaller ones at the same time (Fig 5B). The recovery patterns of the PEGs described by mathematical simulation agree with the recovery pattern found in the uraemic patients and in the control group (Figs 2, 4, and 5A and B). The breakpoint, however, varies only between $397-$ 408 daltons (data not shown), when the renal excretion capacity is reduced from $150 \%$ to $20 \%$ in the mathematical model. In addition, the changed relative recovery of the individual molecules was much less pronounced in the mathematical model (Fig 5B) than in the data from the experimental groups (Fig 4). When looking at the results obtained by the mathematical model it must be remembered that the model is based on data obtained form perfusion studies in $\operatorname{man}^{2}$ and from results gained after intravenous administration of PEGs in pigs. ${ }^{24}$

The proposal that there is increased intestinal permeability (larger average pore size $\mathrm{e}^{35}$ ) in the uraemic patients is a logical one supported by several observations: (1) increased breakpoint in the uraemic group; (2) smaller regression coefficient in the uraemic group; (3) relatively higher urinary recovery of the larger molecules in the uraemic group. The results from intravenous injection of PEGs in rats with chronic uraemia also suggest that the mucosal membranes have different permeability, which shows up in the urinary recovery of PEGs. ${ }^{20}$

These findings suggesting an increased permeability to larger molecules, agree with recent observations in rats, where increased intestinal permeability was shown in acute uraemia ${ }^{36}{ }^{37}$ and in those with chronic renal failure. ${ }^{19}$ Moreover, increased permeability of the blood brain barrier towards inert molecules in chronic uraemic rats has been shown by other investigators. ${ }^{38}$

Shortening of the villi, elongation of the crypts, and infiltration of lamina propria with inflammatory cells have previously been seen in patients with chronic renal failure..$^{10-13}$ Indeed, transmigration of polymorphonuclear cells has been observed to increase the permeability of larger molecules, probably via paracellular pathways. ${ }^{39}$ Increased intestinal permeability has also been shown in mucosal inflammation, as in Crohn's disease. ${ }^{40} 41$ Moreover, several studies have suggested that the bacterial flora of the gut is altered in chronic uraemia and that bacteria associated materials could be implicated in the pathogenesis of this disorder ${ }^{6-94243}$ In fact, enterotoxin from Escherichia coli and synthetic peptides which mimic bacterial peptides are known to increase the intestinal permeability to large molecules - for example dextran $3000 .^{44-47}$ These observations may explain the impaired gut barrier in uraemic subjects.

An alternative explanation is the accumulation of harmful, endogenous low molecular weight substances in serum in the uraemic state. ${ }^{98}$ These uraemic toxins could also affect the intestinal integrity and allow larger molecules to pass more freely over the mucosal barrier than under normal conditions.

In conclusion, the results suggest that despite the reduced over all recovery there is an increased leakage of the larger PEG molecules (414-898 daltons PEG in the test mixture) in chronic uraemic patients. An explanation could be open- 
ing of the paracellular pathways, particularly the tight junctions - for example by bacterial peptides or oligopeptides accumulated in plasma, or both. A possible effect is an impaired barrier function in the intestinal wall towards potential toxic substances in the intestinal lumen. The results encourage further efforts to identify and isolate the causative agent(s) and to delineate the precise mechanisms of the altered mucosal barrier properties in chronic uraemia.

The excellent assistance of Anita Sjö and Gunnel Karlsson is gratefully acknowledged. This research was supported by grants from the Swedish Medical Research Council (Project No 6251), the Swedish Society of Medicine, King Gustaf the Vth 80-Year Foundation, the Professor Nanna Svartz Foundation, the Medical Research Council of the Swedish Life Insurance Companies and Östergötlands Läns Landstings Forskningsfond.

1 Tomasi TB Jr. The immune system of secretions. Englewood Cliffs, New Jersey: Prentice Hall, 1976: 93-108.

2 Chadwick VS, Phillips SF, Hoffman AF. Measurements of intestinal permeability using low molecular weight polyethylene glycols (PEG 400). II. Application to normal and abnormal permeability states in man and animals. Gastroenterology 1977; 73: 247-51.

3 Johansen K, Stintzing G, Magnusson KE, et al. Intestinal permeability assessed with polyethylene glycols in children with diarrhea due to rotavirus and common bacterial pathogens in a developing community. F Pediatr Gastroenterol Nutr 1989; 9: 307-13.

4 Stenhammar L, Fälth-Magnusson K, Jansson G, Magnusson $\mathrm{KE}$, Sundqvist $\mathrm{T}$. Intestinal permeability to inert sugars and different-sized polyethyleneglycols in children with celiac different-sized polyethyleneglycols in children with

5 Katz KD, Hollander D. Intestinal mucosal permeability and rheumatical diseases. Baillieres Clin Rheumatol 1989; 3: 27184 .

6 Simenhoff ML, Asatoor AM, Milne MD, Zilva JF. Retention of aliphatic amines in uraemia. Clin Sci 1963; 25: 65-77.

7 Simenhoff ML. Metabolism and toxicity of aliphatic amines. Kidney Int 1975; 7: S-314-7.

8 Mitch WE. Effects of intestinal flora on nitrogen metabolism in patients with chronic renal failure. Am f Clin Nutr 1978; 31 : $1594-600$.

9 Bergström J, Fürst P. Uremic toxins. In: Drukker W, Parsons FM, Maher JF, eds. Replacement of renal function by dialysis. Boston: Nijhoff Publishing, 1983: 354-90.

10 Denneberg T, Lindberg T, Berg NO, Dahlqvist A. Morphology, dipeptidases and disacchardidases of small intestinal mucosa

11 Goldstein DA, Horowitz RE, Petit S, Haldimann B, Massry S. The duodenal mucosa in patients with renal failure: Response to 1,25(OH), D, Kidney Int 1981; 19: 324-31.

12 Vaziri ND, Dure-Smith B, Miller R, Mirahmadi MK. Pathology of gastrointestinal tract in chronic hemodialysis patients: an autopsy study of 78 cases. Am $\mathcal{F}$ Gastroenterol 1985; 80: 608-11.

13 Arvanitakis C, Nakos V, Kalekou-Greka H, Tourkantonis A. Small intestinal function and structure in patients with chronic renal failure. Clin Nephrol 1988; 29: 235-43.

14 Walker WA. Intestinal transport of macromolecules. In: Johnson R, ed. Physiology of the gastrointestinal tract. New York: Raven Press, 1981: 1271-90.

15 Volkheimer G. Passage of particles through the wall of the gastrointestinal tract. Environ Health Perspect 1974; 9: 21525.

16 Lifschitz C. Intestinal permeability. $\mathcal{F}$ Pediatr Gastroenterol Nutr 1985; 4: 520-2.

17 Lifschitz C, Shulman R. Intestinal permeability tests: are they clinically useful? F Pediatr Gastroenterol Nutr 1990; 10: 2837.

18 Ma T, Hollander D, Krugliak P, Katz K. PEG 400, a hydrophilic molecular probe for measuring intestinal permeability. Gastroenterology 1990; 98: 39-46.

19 Magnusson M, Magnusson K-E, Sundqvist T, Denneberg T. Increased intestinal permeability to differently sized polyethylene glycols in uremic rats: effects of low- and highprotein diets. Nephron 1990; 56: 306-11.

20 Magnusson M, Magnusson K-E, Sundqvist T, Denneberg T. Urinary excretion of differently sized polyethylene glycols after intravenous administration in uremic and control rats: effects of low and high-protein diets. Nephron 1990; 56: 312

16. 16 -älth-Magnusson K, Kjellman M, Magnusson K-E, Sundqvist $T$. Intestinal permeability in healthy and allergic subjects before and after sodium-cromoglycate treatment assessed with different-sized polyethylene glycols (PEG 400 and PEG 1000). Clin Allergy 1984; 14: 277-86.

22 Sundqvist T, Sjödahl R, Magnusson KE, Stjernström I, Tagesson C. Passage of molecules through the wall of the intestinal tract. II. Application of low-molecular weight polyethylene glycol and a deterministic mathematical filter polyethylene glycol and a deterministic mathematical filter Gut 1980; 21: 208-14.

23 Sundqvist T, Tagesson C, Magnusson KE. Simulation of a multi-compartment model for the intestinal permeability to low-molecular-weight probes (polyethyleneglycol 400). $\mathscr{I}$ Math Biosci 1981; 56: 287-309.

24 Sundqvist T, Magnusson KE, Tagesson C. Characterization of size-dependent exchange of PEG molecules between the blood and the extravascular space in pig. Comput Biomed Res 1988; $21: 110-6$.

25 Brunetto AL, Pearson ADJ, Gibson R, Bateman DN, Rashid MU, Laker MF. The effect of pharmacological modification of gastric emptying and mouth-to-caecum transit time on the absorption of sugar probe marker molecules of intestinal permeability in normal man. Eurf Clin Invest 1990; 20: 279 84.

26 Shaffer CB, Critchfield FH, Carpenter CP. Renal excretion and volume distribution of some polyethylene glycols in the dog. Am 7 Physiol 1948; 152: 93-9.

27 Berglund F. Renal clearance of inulin, polyfructosan-S and a polyethylene glycol (PEG 1000) in the rat. Acta Physiol Scand $1965: 64: 238-44$

28 Berglund $F$. Renal excretion and volume distribution of polyethylene glycol (PEG) in the rat and the dog. Acta Physiol Scand 1968; 19: 20A-1.

29 Tagesson C, Sjödahl R. Passage of molecules through the wall of the gastrointestinal tract. Urinary recovery of differentsized polyethylene glycols after intravenous and intestinal deposition. Scand f Gastroenterol 1984; 19: 315-20.

30 Philipsen EK, Batsberg W, Christensen AB. Gastrointestinal permeability to polyethylene glycol: an evaluation of urinary recovery of an oral load of polyethylene glycol as a parameter of intestinal permeability in man. Eur $\mathcal{F}$ Clin Invest 1988; 18 : $139-45$.

31 Saweirs WM, Andrews DJ, Low-Beer TS. The double sugar test of intestinal permeability in the elderly. Age Ageing 1985; 14:312-5.

32 Black DA. Intestinal permeability in the elderly [Letter]. Dig Dis Sci 1988; 33: 382 .

33 Magnusson KE, Sundqvist T, Sjödahl R, Tagesson C. Altered intestinal permeability to low-molecular-weight polyethyleneglycols (PEG 400) in patients with Crohn's disease. Acta Med Scand 1983; 149: 323-7.

34 Fälth-Magnusson K, Kjellman NIM, Sundqvist T, Magnusson KE. Gastrointestinal permeability in atopic and nonatopic mothers, assessed with different-sized polyethylene glycols (PEG 400 and PEG 1000). Clin Allergy 1985; 15: 565-70.

35 Sundqvist $T$ and Magnusson KE. Modelling of intestinal permeability in man to polyethylene glycols (PEG 400 and PEG 1000). Acta Physiol Scand 1985; 125: 289-96.

36 Kimura T, Kobayashi A, Kobayashi $M$, et al. Intestinal absorption of drugs in rats with glycerol-induced acute renal failure. Chem Pharm Bull 1988; 5: 1847-56.

37 Yamashita S, Takahashi M, Masada M, et al. Effect of experimental acute renal failure of a polar drug in rat jejunum: An electrophysiological analysis. Chem Pharm Bull jejunum: An electrop

38 Fishman RA. Permeability changes in experimental uremic encephalopathy. Arch Intern Med 1970; 126: 835-7.

39 Nash S, Stafford J, Madara JL. The selective and superoxideindependent disruption of intestinal epithelial tight junctions during leukocyte transmigration. Lab Invest 1988; 59 : $531-7$

40 Olaison G, Leandersson P, Sjödahl R, Tagesson C. Intestinal permeability to polyethyleneglycol 600 in Crohn's disease. Peroperative determination in a defined segment of the small intestine. Gut 1988; 29: 196-9.

41 Hollander D. Crohn's disease - a permeability disorder of the tight junction? Gut 1989; 29: $1621-4$.

42 Simenhoff ML, Burke JF, Saukkonen JJ, et al. Amine metabolism and the small bowel in uraemia. Lancet 1976; ii: 818-21.

43 Simenhoff ML, Saukkonen JJ, Burke JF, et al. Bacterial population of the small intestine in uremia. Nephron 1978 22: 63-8.

44 Magnusson KE, Dahlgren C, Siölander A. Effect of N-formulated methionyl-phenylalanine (FMP) and - methionylleucyl-phenylalanine (FMLP) on gut permeability. Inflammation $1985 ; 4: 365-73$

45 Magnusson KE, Kihlström E, Sundqvist T. Effect of cholera toxin on rat intestinal permeability assessed with fluorescen dextran 3000. FEBS Microbiol Lett 1985; 29: 15-8.

46 Magnusson KE, Kihlström E, Sundqvist T. Elevation of ra intestinal permeability by enterotoxigenic Escherichia coli in comparison to non-toxigenic $E$ coli and Salmonella typhimurium. Application of fluorescent dextran 3000 as permeability probe. FEBS Microbiol Lett 1986; 34: 199204.

47 v Ritter C, Sekizuka E, Grisham MB, Granger DN. The chemotactic peptide N-Formyl Methionyl-LeucylPhenylalanine increases mucosal permeability in the distal ileum of the rat. Gastroenterology 1988; 95: 651-6.

48 Bergström J, Fürst P, Zimmerman L. Uremic middle molecules exist and are biologically active. Clin Nephrol $1979 ; 11$ : $229-38$. 